\title{
Argyria: Report of a case associated with abnormal electroencephalographic and brain scan findings
}

\author{
MARC J. ROSENBLATT, D.O \\ TYLER C. CYMET, B.A., B.S \\ Hollywood, Florida
}

The argyria in the 83-year-

old patient in this case had developed 40 years earlier secondary to the use of Argyrol brand nasal packings, which had been used for the treatment of sinusitis over a 2-year period.

Discolorations of the patient's skin varied from slightly silver hues to highly pronounced silver-blue pigmentations. Computed tomographic scans revealed that the patient had ill-defined lucencies in the parietal areas of the brain bilaterally. Seizure activity of the grand mal type also was exhibited by the patient. The findings from this case are examined in light of the current literature regarding argyria. The benign nature of argyria is questioned. Causes of argyria, complications, the course of the disorder, and the efficacy of various treatments are reviewed.

Argyria results from excessive exposure to silver salts or silver protein colloids. Current thought holds that silver has very low systemic toxicity. However, because of insufficient data regarding the effects of exposure to relatively larger amounts or continued exposure to even small amounts, silver salts have been given a toxicity rating of 4 . Therefore, physicians should be cautious in their use of compounds containing silver salts. Doses of 50-500 $\mathrm{mg} . / \mathrm{kg}$. are lethal. ${ }^{1}$

When silver salts are applied over the skin, localized argyria results. These same compounds, when applied to mucosal surfaces, inhaled, or injected into the body, will cause generalized argyria. In localized argyria, silver will enter the body through exocrine sweat glands and remain in the skin. ${ }^{2,3}$ In generalized argyria, silver is deposited first in the connective tissues of the kidney, liver, and spleen ${ }^{4}$ and in the eye; ${ }^{5}$ it also can be detected in the blood. ${ }^{6}$ The skin is the last organ to be af- fected in generalized argyria. ${ }^{7}$

The causes of argyria are known, and the disorder is completely preventable, but argyria is still seen periodically. The use of folk remedies, overprescription of drugs containing silver, and occupational exposure to silver compounds ${ }^{5,8}$ (Table 1) are three important causes. Current silver-containing medications (Table 2) include silver nitrate pills for gastrointestinal ailments, ${ }^{9}$ nosedrops for sinusitis, ${ }^{10}$ antismoking lozenges, ${ }^{11,12}$ and sulfadiazine, mafenide, and sulfasalazine which are used to limit infection..$^{2,13}$ Bladder irrigations and abdominal surgery also have been implicated in argyria. The "amalgam tatoo," permanent silver coloring on the gums around an area of a filled tooth, occurs frequently. ${ }^{14}$ It is not clear whether this phenomenon represents localized or generalized argyria.

Generalized argyria is very difficult to detect in its initial stages; it usually is not recognized until the skin starts to take on the silver-blue color that is characteristic of the disease. The change in skin pigmentation itself can lead to misdiagnosis. Argyria often is mistaken for cyanosis or cyanotic heart disease ${ }^{10}$ methemoglobinemia, metastatic melanoma, melanuria, or hematochromatosis..$^{15}$ The use of antimalarial drugs also may cause a condition that mimics argyria. The diseases to be included in differential diagnosis of argyria are listed in Table 3.

Levels of silver in the blood can be monitored and will provide a sure sign of the disease long before the skin becomes discolored. Ocular pigmentation, which frequently is present in argyria, occurs earlier than changes in skin pigmentation. ${ }^{5}$ On the conjunctiva, pigmentary changes are seen at the caruncle and semilunar folds. Corneal pigmentation is exhibited by the appearance of a pigmented inner ring adjacent to the limbus. Patients may complain of decreased night vision. The ankles also may exhibit early signs of argyria, ${ }^{18}$ and the discoloration is also found on the proximal half of the 
TABLE 1. OCCUPATIONS THAT ARE AT HIGH RISK FOR ARGYRIA.

\begin{tabular}{|c|c|}
\hline Occupation & $\begin{array}{l}\text { Silver compounds utilized } \\
\text { in occupation }\end{array}$ \\
\hline Copy machine operator & $\begin{array}{l}\text { p-methyaminophenol sulfate- } \\
\text { hydroquinone }\end{array}$ \\
\hline $\begin{array}{l}\text { Furnaceman in melting } \\
\text { plants }\end{array}$ & Crude ore refinement \\
\hline Manufacturing & $\begin{array}{l}\text { Silver oxide-zinc for making } \\
\text { batteries }\end{array}$ \\
\hline \multicolumn{2}{|l|}{ Mining } \\
\hline $\begin{array}{l}\text { Photographic processing } \\
\text { and developing }\end{array}$ & $\begin{array}{l}\text { Silver halides, nitrates, and } \\
\text { thiosulfates }\end{array}$ \\
\hline $\begin{array}{l}\text { Printing (pressman and } \\
\text { camera operators, } \\
\text { typesetters) }\end{array}$ & $\begin{array}{l}\text { p-methyaminophenol sulfate- } \\
\text { hydroquinone } \\
\text { Silver halides, nitrates, and } \\
\text { thiosulfates }\end{array}$ \\
\hline Silversmiths and jewelers & \\
\hline
\end{tabular}

fingernails. ${ }^{17}$ If the argyria is occupationally related, the changes in the skin color may be limited to exposed areas on the body. Changes in pigmentation are most evident on parts of the body that are exposed to the sun. The discolorations of argyria may result from silver stimulating the activity of melanocytes as well as from the deposition of silver in the dermis of the skin. ${ }^{3,6}$

The effects of exposure to silver may not be immediate. Even if there is no exposure to silver for years, the condition may suddenly become worse through exposure to the sun. That is probably the case in the patient we are presenting.

\section{Report of case}

An 81-year-old woman was brought into the emergency room after an accident with a nursing home bedpan resulted in a contusion in the area of her right kidney. The patient also complained of arthritis and sinusitis. Another reason that the nursing home representative gave for transferring this patient to the hospital was that "her color was getting worse." The medical history was incomplete because the patient suffered from senile dementia. She was disoriented as to time and place and otherwise confused, and she later proved to be incontinent of urine.

On physical examination, the patient was noted to have blue lacunae, silver facies, and silver nasal mucosa, and it initially was thought that she was cyanotic. Her vital signs were as follows: blood pressure, $124 / 66 \mathrm{~mm}$. $\mathrm{Hg}$; pulse rate, 84 beats/minute; respiratory rate, $28 / \mathrm{min}$.; and temperature, 101.6 F. Her lungs were clear on auscultation, and there were no grossly abnormal cardiopulmonary findings. Urine cultures were negative with lead levels in the normal range. No silver showed up in the blood. The patient's medical records were obtained, and they revealed that some 40 years earlier she had used Argyrol nasal packings once a week for a period of 2 years as sinusitis therapy. During that time, her skin color had changed, and she had been diagnosed as having argyria.
There had not been much improvement in the skin color since then, nor had it worsened.

The diagnosis of argyria was made the morning after admission when the differential diagnosis of silver blue skin was reviewed and the initial discoloration noted. The prior history of argyria use was revealed in the medical records. The patient's skin color was different than that described as having resulted from her initial exposure of silver. The medical records did state that the use of argyria was discontinued because of the patient's subjective feeling of skin discoloration. No silver was detected in the blood during the present hospitalization. The appearance of the patient's mucosal surfaces, especially the nasal mucosa, was light pink with areas of bluish black discoloration.

Three days after admission, the patient began to show seizure activity of the grand mal type. Computed tomographic (CT) scanning of the brain revealed ill-defined lucencies in both the left and right parietal areas, with no associated masses. There also was evidence of mild atrophy, which was both central and cortical. Both hemispheres were well perfused. The electroencephalogram (EEG) was abnormal with asymmetry of the background activity.

Punch biopsy of the left nasolabial fold was performed, and hematoxylin/eosin-stained sections revealed fine granular particles in and about adnexal structures.

The patient was given Dilantin, which controlled the seizures. The patient's diet was modified so that she received all of the essential nutrients, and was discharged after her Dilantin levels were stabilized. The staff at the nursing home where the patient was living were notified of the patient's sensitivity to the sun, along with the expected results to sun exposure. ${ }^{19}$

\section{Case discussion}

The patient's 2 years of Argyrol nasal packings most probably was the cause of her argyria. Her silver-blue color caused some confusion at first, and she was misdiagnosed as being cyanotic. Her color was one of the reasons that she was brought into the hospital. She had just moved into a new nursing home, and the staff there were not aware of her condition. Therefore, she may have been taken out in the sun more often than before, which could have led to her discoloration becoming more pronounced.

It is important to note that the CT scans revealed ill-defined lucencies of unknown origin, and that the patient had an abnormal EEG pattern. No other physical findings were associated with the patient's argyria. These disorders could have been caused by the silver that was absorbed through the nasal mucosa. There would be no need for the silver to cross the blood brain barrier after entering the body via this method. Parietal lobe lesions are consistent with personality disorders, including senile dementia. The fact that the lesions were bilateral seems significant. There are other cases in which 
metals have been reported to deposit in a certain area of the brain. One such example would be Wilson's disease, in which copper causes large cavitations in the basal ganglion of the brain bilaterally. ${ }^{17}$

\section{Comments}

The effects of argyria usually are assumed to be primarily cosmetic. There is a definite increase in melanin pigmentation, which is stimulated by the deposition of silver. In localized argyria, the highest concentrations are to be found around the basal exocrine sweat glands ${ }^{19}$ and around hair follicles. ${ }^{20}$ The deposits are round or oval bodies in localized argyria; occasionally the silver will form concentric rings. ${ }^{19}$ Silver is seen throughout the dermis, but it is almost never found in the epidermis. There are aggregations of phagolysosomes in the cell, and silver is found within the mitochondria. ${ }^{19}$ When toxic doses of silver are introduced into the body, there are definite cidal effects on the mitochondria. ${ }^{18}$ Silver also is deposited around basement membranes and blood vessels, and greyish-blue discoloration is evident on the larynx, gastrointestinal tract, peritoneum, kidneys, testicles, and liver. There also are definite accumulations of silver in connective tissue; these are seen most frequently in patients suffering from senile elastosis. ${ }^{19}$

For the most part, the effects of silver on certain physiologic responses generally have not been determined. Silver has been implicated as a cause of decreased night vision, ${ }^{4}$ a cause of mild chronic bronchitis, a possible cause of idiopathic thrombocytopenia, an inhibitor of enzyme activity, and a nephrotoxin. ${ }^{8}$ One study ${ }^{8}$ demonstrated a definite correlation between exposure to silver salts (silver nitrate or silver oxide) and abdominal pain. This pain, which was described as "burning in quality," was relieved with the use of antacids.

There still is no effective treatment for argyria. It is known that exposure to the sun will exacerbate the condition by a process similar to the developing of film. Although the patient discussed in this article abstained from silver compounds for 40 years, there was no appreciable improvement/worsening in her skin color until she changed her lifestyle to one that possibly included increased exposure to the sun.

There have been some anecdotal reports on the improvement of the skin color of patients suffering from argyria. It is not clear whether the beneficial effect was accomplished by removal of the silver or by bleaching of the melanin. The treatment that was most often presented was intradermal injections of potassium ferricyanide-thiosulfate sodium.

\begin{tabular}{|c|c|}
\hline Use & Therapeutic agents \\
\hline Antibacterial cleansing & Silver nitrate ointments \\
\hline Antismoking aid & $\begin{array}{l}\text { Silver acetate and } \\
\text { ammonium chloride } \\
\text { lozenges }\end{array}$ \\
\hline Aphthae treatment & Silver nitrate sticks \\
\hline Burn therapy & $\begin{array}{l}\text { Silver sulfadiazine, silver } \\
\text { sulfacetamide }\end{array}$ \\
\hline $\begin{array}{l}\text { Bleeding control (especially } \\
\text { gingival bleeding caused } \\
\text { by dentures) }\end{array}$ & $\begin{array}{l}\text { Silver nitrate in topical } \\
\text { drops }\end{array}$ \\
\hline Dental caries filling & Silver amalgam \\
\hline Folk remedies for chronic & Silver salts \\
\hline laryngitis, gastric & Silver colloids \\
\hline $\begin{array}{l}\text { discomfort, nervous system } \\
\text { disorders, epilepsy, tabes } \\
\text { dorsalis, and chorea minor }\end{array}$ & $\begin{array}{l}\text { Argento-mercapto-3 } \\
\text { hydroxy 2-propane sodium } \\
\text { sulfonate m-acetyl amino } \\
\text { p hydroxy phenyl sodium } \\
\text { arsenate }\end{array}$ \\
\hline Indigestion alleviation & Silver-containing antacids \\
\hline $\begin{array}{l}\text { Ophthalmia prophylaxis in } \\
\text { neonates }\end{array}$ & Silver nitrate drops \\
\hline $\begin{array}{l}\text { Perinatal prophylaxis for } \\
\text { gonorrhea }\end{array}$ & Silver nitrate drops \\
\hline Sinusitis therapy & Silver protein nasal packings \\
\hline Suturing & $\begin{array}{l}\text { Silver sutures (used } \\
\text { experimentally) }\end{array}$ \\
\hline \multirow[t]{5}{*}{ Wound treatment } & Silver \\
\hline & Sulfadiazine \\
\hline & Mafenide \\
\hline & Sulfasalazine \\
\hline & Silver sulfacetamide \\
\hline
\end{tabular}

TABLE 3. DIFFERENTIAL DIAGNOSIS FOR ARGYRIA.

Addison's disease

Cyanosis

Cyanotic heart disease

Drug-induced pigmentations

(antimalarial agents - Atabrine,

amodiaquine hydrochloride,

chloroquine, phenopthalein)

Melanuria

Metastatic melanoma

(melanosis)

Methemoglobinemia

Pigmentation from heavy metals

Chrysiasis (gold)

Hematochromatosis (hemosiderin and melanin)

Hydrargyrosis (mercury)

Onchronosis (hemogentisic acid)

Wilson's disease (copper)

Polycythemia

Pseudomonas paronychia

Pseudomonas pyocyanea

Unfortunately, this photographic reducing solution became better known for its ability to produce pain than for its effects on the silver deposits. ${ }^{15}$ Other agents include potassium iodide and methenamine (Callargol). ${ }^{6}$ No appreciable success has been obtained with any treatment.

\section{Summary}

Although argyria is not the first thing that you 
think of when a person presents with a bluish discoloration, it must be in the differential. A thorough occupational history is needed as well as a history of medications taken in order to suggest argyria.

The authors wish to express their appreciation to Michael Baron and Robert Crook for their research and consultation.

1. Gosselin, R.E., Smith, R.P., and Hodge, H.C.: Clinical toxicology of commercial products. Ed. 5. Williams and Wilkins, Baltimore, 1984

2. Buckley, W.R.: Localized argyria. Arch Dermatol 88:531-9, Nov 63

3. Buckley, W.R., Oster, C.F., and Fassett, D.W.: Localized argyria. II. Chemical nature of the silver containing particles. Arch Dermatol 92:697-705, Dec 65

4. Marshall, J.P., and Schneider, R.P.: Systemic argyria secondary to topical silver nitrate. Arch Dermatol 113:1077-9, Aug 77

5. Moss, A.P., et al.: The ocular manifestations and functional effects of occupational argyrosis. Arch Ophthalmol 97:906-8, May 79

6. Pariser, R.J.: Generalized argyria. Clinicopathologic features and histochemical studies. Arch Dermatol 114:373-7, Mar 78

7. Gherardi, R., et al: Human generalized argyria (letter). Arch Pathol Lab Med 108:181-2, Mar 84

8. Rosenman, K.D., Moss, A., and Kon, S.: Argyria. Clinical implications of exposure to silver nitrate and silver oxide. J Occup Med 21:430-5, Jun 79

9. Ronchese, F: Argyrosis and cyanosis-melanosis and cyanosis. Arch Dermatol 80:277-82, Sep 59

10. Rich, L.L., Epinette, W.W., and Nasser, W.K.: Argyria presenting as cyanotic heart disease. Am J Cardiol 30:290-2, Aug 72
11. Shelton, D., and Goulding, R.: Silver poisoning associated with an antismoking lozenge (letter). Br Med J 1:267, 27 Jan 79

12. MacIntyre, D., et al.: Silver poisoning associated with antismoking lozenge. Br Med J 6154:1749-50, 23-30 Dec 78

13. Sladkin, K.R., and Lynfield, Y.: Blue lady. A case of argyria. Cutis 22:321-23, Sep 78

14. Plack, W., and Bellizzi, R.: Generalized argyria secondary to chewing photographic film. Report of a case. Oral Surg 49:504-6, Jun 80

15. Smith, S.Z., et al.: Argyria. Arch Dermatol 117:595-6, Sep 81

16. Rupp, T.: Unusual localized case of argyria. Internat J Dermatol 18:589-90, 18 Sep 79

17. Taylor, H.R., and Martin, S.A.: Neurologic disorders associated with endocrine and metabolic disorders. In Tice's Practice of medicine, vol. 10 Harper and Row, New York, 1979, pp. 44-45

18. Plewig, G., Lincke, H., and Wolff, H.H.: Silver-blue nails. Acta Derm Venereol 57:413-9, 1977

19. Prose, P.H.: An electron microscopic study of human generalized argyria. Am J Pathol 42:293-9, Mar 63

20. Pezzarossa, E., Alinovi, A., and Ferrari, C.: Generalized argyria. J Cutan Pathol 10:361-3, Oct 83

Bleehen, S.S., et al.: Occupational argyria. Light and electron microscopic studies and x-ray microanalysis. Br J Dermatol 104:19-26, Jan 81 Harman, R.R.: Argyria. Br J Dermatol 97S:60-1, Jul 77

Accepted for publication in August 1986. Updating, as necessary, has been done by the authors.

Dr. Rosenblatt is director of the Department of Physical Medicine and Rehabilitation, Southeastern College of Osteopathic Medicine, North Miami Beach. Mr. Cymet is a senior student at SECOM.

Mr. Cymet, 4450 North Hills Drive, Hollywood, Florida 33021. 
NAME AND OFFICE ADDRESS (Print Clearly)

\begin{tabular}{|ll}
\hline Name & AOA No.
\end{tabular}
group, check the ONE which you prefer to have receive exhibit income credit for your attendance.

SPECIFY ALUMNI LUNCHEON

\section{SECTION I}

American Academy of Osteopathy

Member

$\$ 175 \dagger$

Guest

American Osteopathic College of Allergy and Immunology

Member

Guest

steopathic College of Dermatology

Member

Guest

College of Osteopathic Emergency Physicians

Member

Guest

ican College of General Practitioners in Osteopathic

Medicine and Surgery

Member

Guest

American College of Neuropsychiatrists

Member

Guest

American Osteopathic College of Pathologists

Member

Guest

merican Osteopathic College of Preventive Medicine

Member

Guest

American Osteopathic College of Rehabilitation Medicine

Member

Guest

American Osteopathic College of Rheumatology, Inc.

Member

Guest

American Osteopathic Academy of Sclerotherapy, Inc.

Member

Guest

American Osteopathic Academy of Sports Medicine

Member

Guest
$\$ 175 t$

\section{SECTION II}

American Osteopathic Association

Member

$\$ 150^{*}$

Adult Guest - With AOA tickets .......... \$ $75^{*}$

Adult Guest - Without AOA tickets ...... no fee + Juvenile Guest ................. no fee +

Intern $\ldots \ldots \ldots \ldots \ldots$ no fee +

Resident ...................... no fee +

Student ..................... no fee +

Adult Guest of Intern, Resident or Student no fee +

Associate Member .................... \$ 50\#

Nonmember ..................... \$425*

Auxiliary to the $A O A$

Member - With AOA tickets ......... \$ $7^{*}$

Member - Without AOA tickets ........ no fee +

\section{SECTION III}

Canadian Osteopathic Association

Member

Nonmember

\section{KEY TO SYMBOLS}

* Includes tickets, for one person, to AOA President's Dinner. In addition, D.O.'s receive College Alumni Luncheon ticket and guests receive ticket to AOA Entertainment for Spouses of D.0.'s.

† Includes tickets, for one person, to AOA President's Dinner and all social functions planned by this individual group. In addition, D.0.'s receive College Alumni Luncheon ticket and guests receive ticket to AOA Entertainment for Spouses of D.0.'s.

+ Individual tickets for social functions may be purchased.

\# Includes ticket, for one person, to AOA President's Dinner.

$\ddagger$ See registration rules on reverse side.

COMPLETE the above FORM (see instructions on reverse side), ATTACH CHECK for registration fee made PAYABLE TO IHE AMERICAN OSTEOPATHIC ASSOCIATION, to cover fees, and RETURN TO:

Convention Office - American Osteopathic Association - 142 E. Ontario St. • Chicago, IL 60611

Registration packets will be mailed out prior to the convention to those who register in advance. Advance registration forms nust be received no later than September 1,1987 . There will be a $\$ 15.00$ late charge for registration in Orlando. Refunds on cancellations will be made if received no later than September 1, 1987. 


\section{REGISTRATION INSTRUCTIONS}

\section{THOSE WHO MAY REGISTER}

Members of the American Osteopathic Association or the Canadian Osteopathic Association, their adult guests (who are not osteopathic physicians) and their children.

Osteopathic physicians who are NOT members of the AOA may register, but are required to pay a fee of $\$ 425.00$. Osteopathic physicians, if eligible, may thereupon apply for AOA membership at the registration desk and, if they are accepted into membership, $\$ 275.00$ of the Nonmember registration fee will be applied to their annual dues. Membership in the Canadian Osteopathic Association may substitute for AOA membership if the doctor is located in Canada.

Students and students' spouses.

Commercial and scientific exhibitors.

\section{HOW TO SELECT REGISTRATION CATEGORY}

\section{D.0.'s}

Check ONLY ONE category for your registration. Participating affiliated organizations are listed under Section I of the form. The American Osteopathic Association registration under Section II and other categories are listed under Section III. Regardless of the category you check, you are entitled to attend ANY of the didactic sessions put on by ANY of the participating organizations. Although membership in a participating affiliated organization is not a requirement to register for the group, AOA membership (or if a doctor is from Canada, Canadian Osteopathic Association membership) is a requirement for registration in ANY of the D.0. registration categories, except for those who have paid the higher Non-member registration fee.

If you are a member of two of the participating affiliated organizations and wish to register for both, you may do so by paying TWO registration fees - one for each group. In such case, CME credit will be allowed for only ONE of the two groups.

\section{GUESTS:}

In addition to checking your category, check the category for all your guests (being sure to indicate the guest's name in the space provided on the form).

The D.0. registration fee does NOT include tickets for anyone other than the doctor. Guests are to be registered either by paying a fee and receiving tickets, or by NOT paying a fee and NOT receiving tickets ("Adult Guest - NO tickets" category, under Section II of the form). If the doctor's guest is to have the same tickets as the doctor, then check the guest category for the group under which the doctor is registering and pay the fee indicated. In such case, however, the D.0. fee includes a College Alumni Luncheon ticket, but the Guest fee does NOT, but may be purchased separately. In addition, the guest registration fee covers a ticket to the AOA Entertainment for Spouses of D.0.'s. Those guests who do not pay a registration fee may purchase separate tickets to meal functions.

\section{TICKETS COVERED BY REGISTRATION FEE}

The fees shown on the registration form are followed by symbols to indicate the tickets which are covered by the fees. To interpret the symbols, see "Key to Symbols," in the box below Section III of the registration form. 


\section{non-insulin-dependent}

\section{Diabetes and compliance}

MicronASE usually provides 24-hour control of blood glucose levels with a once-a-day dosage. Over $80 \%$ of patients treated with MiCRONASE have been controlled by dosage regimens of $10 \mathrm{mg}$ or less per day. To enhance compliance, MiCRONASE Tablets may be administered with breakfast or the first main meal.

All sulfonylureas, including MicronASE, can cause severe hypoglycemia. Proper patient selection, dosage, and instructions are important.

No other oral antidiabetic agent fits the realities of life better than

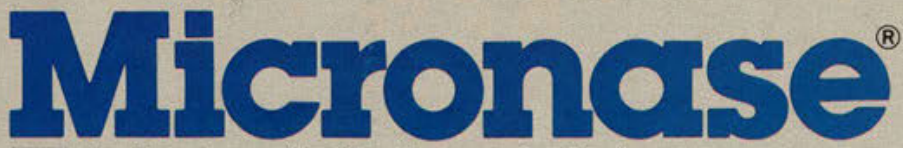

Tablets (glyburide)

Usual starting dosage $-2.5 \mathrm{mg}$ to $5 \mathrm{mg}$ once a day

When diet alone fails...MICRONASE

Please see adjacent page for brief summary of prescribing information.

\section{Upjohn}



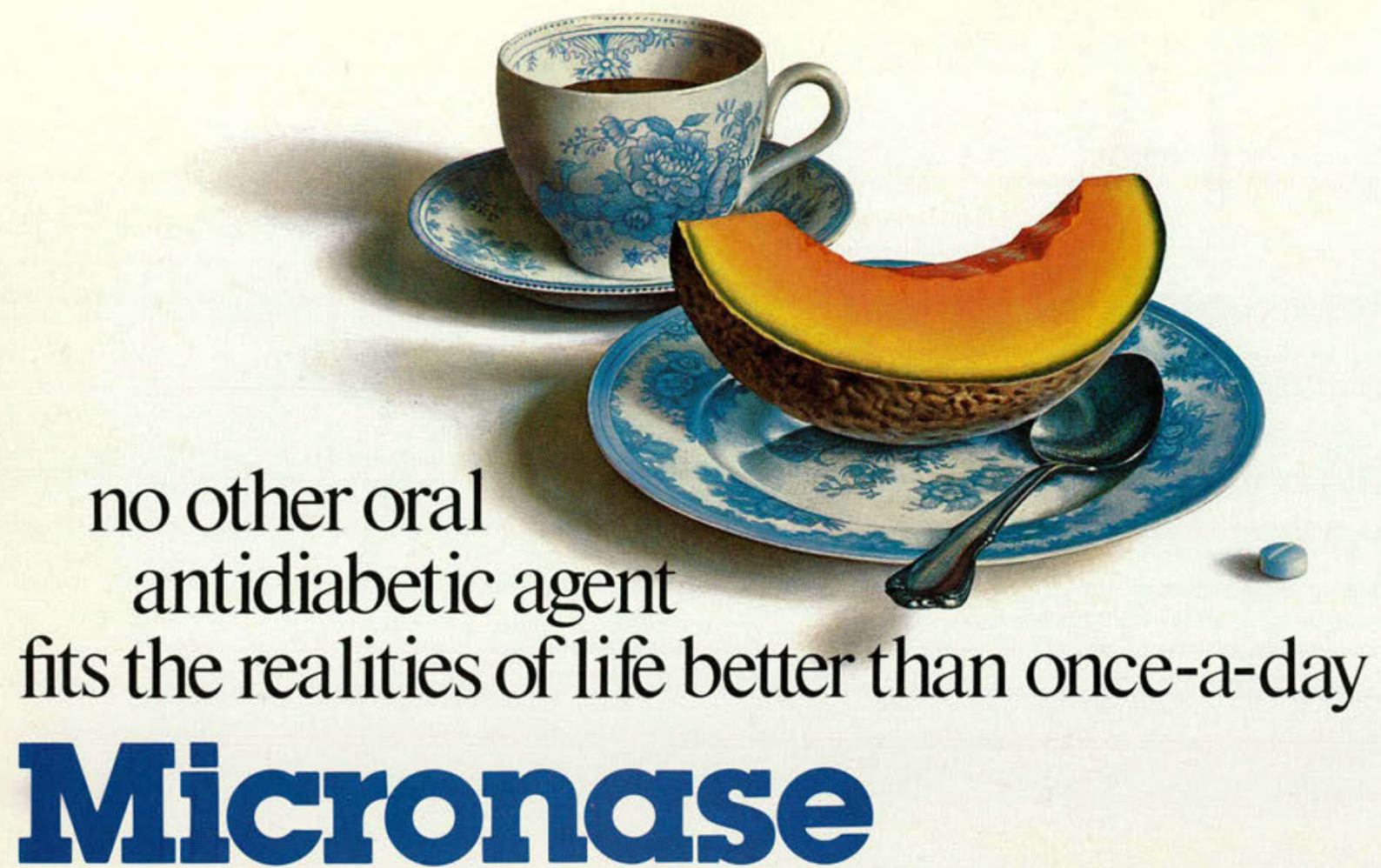

Some patients, particularly those receiving more than $10 \mathrm{mg}$ daily, may have a more satisfactory response with twice-a-day dosage.

Micronase Tablets (glyburide)

CONTRAINDICATIONS: MICRONASE Tablets are contraindicated in patients with: 1. Known hypersensitivity or allergy to the drug. 2. Diabetic ketoacidosis, with or without coma. This condition should be treated with insulin. 3 . Type I diabetes mellitus, as sole therapy.

SPECIAL WARNING ON INCREASED RISK OF CARDIOVASCULAR MORTALITY: The administration of oral hypoglycemic drugs has been reported to be associated with increased cardiovascular mortality as compared to treatment with diet alone or diet plus insulin. This warning is based on the study conducted by the University Group Diabetes Program (UGDP), a long-term prospective clinical trial designed to evaluate the effectiveness of glucose-lowering drugs in preventing or delaying vascular complications in patients with noninsulin-dependent diabetes. The study involved 823 patients who were randomly assigned to one of four treatment groups (Diabetes, 19 [Suppl 2):747-830, 1970).

UGDP reported that patients treated for 5 to 8 years with diet plus a fixed dose of tolbutamide ( 1.5 grams per day) had a rate of cardiovascular mortality approximately $2 y_{2}$ times that of patients treated with diet alone. A significant increase in total mortality was not observed, but the use of tolbutamide was discontinued based on the increase in cardiovascular mortality, thus limiting the opportunity for the study to show an increase in overall mortality. Despite controversy regarding the interpretation of these results, the findings of the UGDP study provide an adequate basis for this warning. The patient shouid be informed of the potential risks and advantages of MICRONASE and of alternative modes of therapy.

Although only one drug in the sulfonylurea class (tolbutamide) was included in this study, it is prudent from a safety standpoint to consider that this warning may apply to other oral hypoglycemic drugs in this class, in view of their close similarities in mode of action and chemical structure.

PRECAUTIONS: General-Hypoglycemia: All sulfonylureas are capable of producing severe hypoglycemia Proper patient selection and dosage and instructions are important to avoid hypoglycemic episodes. Renal or hepatic insufficiency may increase the risk of serious hypoglycemic reactions. Elderly, debilitated or malnourished patients, and those with adrenal or pituitary insufficiency, are particularly susceptible to the hypoglycemic action of glucose-lowering drugs. Hypoglycemia may be difficult to recognize in the elderly and in people who are taking beta-adrenergic blocking drugs. Hypoglycemia is more likely to occur when and in people who are taking beta-adrenergic blocking drugs. Hypoglycemia is more likely to occur when
caloric intake is deficient, after severe or prolonged exercise, when alcohol is ingested, or when more than caloric intake is deficient, after severe or prolonged exercise, when alcohol is ingested, or when more than
one glucose lowering drug is used. Loss of Control of Blood Glucose: In diabetic patients exposed to stress such as fever, trauma, infection or surgery, a loss of control may occur. It may then be necessary to discontinue MICRONASE and administer insulin. Adequate adjustment of dose and adherence to diet should be assessed before classifying a patient as a secondary failure. Information for Patients. Patients should be informed of the potential risks and advantages of MICRONASE and of alternative modes of therapy. They also should be informed about the importance of adherence to dietary instructions, of a regular exercise program, and of regular testing of urine and/or blood glucose. The risks of hypoglycemia, its symptoms and treatment, and conditions that predispose to its development should be explained to patients and responsible family members. Primary and secondary failure should also be explained. Laboratory Tests: Response to MICRONASE Tablets should be monitored by frequent urine glucose tests and periodic blood glucose tests. Measurement of glycosylated hemoglobin levels may be helpful in some patients. Drug Interactions: The hypoglycemic action of sulfonylureas may be potentiated by certain drugs including nonsteroidal antiinflammatory agents and other drugs that are highly protein bound salicylates, sulfonamides, chloramphencol, probenecid, COUmarins, monoamine oxidase inhibitors, and beta adrenergic blocking agents. Certain ingerglycemia and may lead to loss of control. These drugs include the thiazides and other diuretics, corticosteroids, phenothiazines, thyroid products, estrogens, oral contraceptives, phenytoin, nicotinic acid, sympathomimetics, calcium channel blocking drugs, and isoniazid. A potential interaction between oral miconazole and oral hypoglycemic agents leading to severe hypoglycemia has been reported. Carcinogenesis, Mutagenesis, and Impairment of Fertility: Studies in rats at doses up to $300 \mathrm{mg} / \mathrm{kg} / \mathrm{day}$ for 18 months showed no carcinogenic effects. Glyburide is nonmutagenic when studied in the Salmonell microsome test (Ames test) and in the DNA damage/alkaline elution assay. Pregnancy: Teratogenic Effects: Pregnancy Category B. Reproduction studies in rats and rabbits have revealed no evidence of impaired fertility or harm to the fetus due to glyburide. There are no adequate and well controlled studies in pregnant women. This drug should be used during pregnancy only if clearly needed. Insulin should be used during pregnancy to maintain blood glucose as close to normal as possible. Nonteratogenic Effects: Prolonged severe hypoglycemia ( 4 to 10 days) has been reported in neonates born to mothers who were receiving a sulfonylurea drug at the time of delivery. MICRONASE should be discontinued at least two weeks before the expected delivery date. Nursing Mothers: Some sulfonylurea drugs are known to be excreted in human milk. Insulin therapy should be considered. Pediatric Use: Safety and effectiveness in children have not been established.

ADVERSE REACTIONS: Hypoglycemia: See Precautions and Overdosage sections. Gastrointestinal Reactions: Cholestatic jaundice may occur rarely; MICRONASE Tablets should be discontinued if this occurs. Gastrointestinal disturbances, e.g. nausea, epigastric fullness, and heartburn, are the most common reactions, having occurred in $18 \%$ of treated patients during clinical trials. They tend to be dose-related and may disappear when dosage is reduced. Liver function abnormalities, including isolated transaminase elevations, have been reported. Dermatologic Reactions: Allergic skin reactions, e.g. pruritus, erythema, urticaria, and morbilliform or maculopapular eruptions, occurred in $1.5 \%$ of treated patients during clinical trials. These may be transient and may disappear despite continued use of MICRONASE; if skin reactions persist, the drug should be discontinued. Porphyria cutanea tarda and photosensitivity reactions have been reported with sulfonylureas. Hematologic Reactions: Leukopenia, agranulocytosis, thrombocytopenia, hemolytic anemia, aplastic anemia, and pancytopenia have been reported with sulfonylureas. Metabolic Reactions: Hepatic porphyria and disulfiram-like reactions have been reported with sulfonylureas: however, hepatic porphyria has not been reported with MICRONASE and disulfiram-like reactions have been reported very rarely. Cases of hyponatremia have been reported with glyburide and all other sulfonylureas, most often
in patients who are on other medications or have medical conditions known to cause hyponatremia or increase in patients who are on other medications or have medical conditions known to cause hyponatremia or increase
release of antidiuretic hormone. (SIADH) secretion has been reported with certain other sulfonylureas, and it has been suggested that these sulfonylureas may augment the peripheral (antidiuretic) action of ADH and /or increase release of $\mathrm{ADH}$

OVERDOSAGE: Overdosage of sulfonylureas, including MICRONASE Tablets, can produce hypoglycemia. If hypoglycemic coma is diagnosed or suspected, the patient should be given a rapid intravenous injection of concentrated ( $50 \%$ ) glucose solution. This should be followed by a continuous infusion of a more dilute (10\%) glucose solution at a rate which will maintain the blood glucose at a level above $100 \mathrm{mg} / \mathrm{dL}$. Patients should be closely monitored for a minimum of 24 to 48 hours, since hypoglycemia may recur after apparent clinical recovery.

Caution: Federal law prohibits dispensing without prescription. Store at controlled room temperature $15^{\circ}-30^{\circ} \mathrm{C}\left(59^{\circ}-86^{\circ} \mathrm{F}\right)$ Dispensed in well closed containers with safety closures. Keep container tightly closed. For additional product information see your Upjohn representative.

\section{Upjohn}

THE UPJOHN COMPANY, Kalamazoo, MI 49001, USA 